\title{
APSICOLOGIA \\ ARGUMENTO \\ A Parentalidade em Foco com Grupos de Pais: o relato de uma experiência
}

ISSN 01037013

Licenciado sob uma licençọ Creative Commans

\section{Parenting in Focus with Parent Groups: Reporting an Experience}

\author{
Mariana de Oliveira Bortolatto ${ }^{[a]}$, Victória Niebuhr Loos $^{[\mathrm{b}]}$, Josiane da Silva Delvan ${ }^{[\mathrm{c}]}$, \\ [a] Psicóloga, Mestranda pela Universidade Federal de Santa Catarina, \\ mariana_bortolatto@hotmail.com \\ [b] Psicóloga, Mestre em Psicologia pela Universidade Federal de Santa Catarina, \\ victorialoos@hotmail.com \\ [c] Psicóloga, Docente do Curso de Psicologia da Universidade do Vale do Itajaí, \\ josidelvan@univali.br
}

\section{Resumo}

Este trabalho refere-se às intervenções realizadas no estágio específico em Psicologia com grupo de pais no programa denominado EducaPais. O programa teve como objetivo o desenvolvimento de habilidades parentais. Fruto de um relato de experiência, o presente trabalho teve como enfoque teórico a Psicologia Positiva, práticas e estilos parentais, habilidades sociais e a teoria Bioecológica do desenvolvimento humano. O programa compreende nove encontros semanais com duração de uma hora e meia cada, sendo pautados nas contribuições e saberes da Psicologia sobre as práticas e estilos parentais. Participaram dos grupos pais ou cuidadores de crianças de zero a oito anos de idade, residentes em uma cidade do litoral norte catarinense. Os encontros abordaram temas como desenvolvimento infantil, raiva, valorização dos comportamentos adequados das crianças, comportamentos inadequados e suas consequências, disciplina, importância da rotina, estabelecimento de limites, estilos parentais e habilidades sociais. Os temas trabalhados relacionados a parentalidade $e$ ao relacionamento entre pais/cuidadores e filhos foram discutidos a partir das diferentes formas de 
configuração familiar existentes no grupo. Os resultados encontrados indicam que programas neste formato contribuem para que os participantes conheçam os modelos parentais eficazes e positivos, bem como aprimorem as competências e práticas parentais. Isto possibilita a criação de ambientes seguros e saudáveis, nos quais os pais percebam a necessidade do envolvimento ativo na criação dos filhos. O trabalho com grupos enquanto espaço de compartilhamento, possibilitou a troca de experiência entre os participantes para a compreensão das similaridades de suas vivências e a elaboração de planos para modificar sua realidade. Também contribuiu para a ressignificação e problematização de práticas educativas vigentes e para a mudança de conduta diante dos comportamentos dos filhos. Entre os desafios encontrados, destaca-se a dificuldade de adesão ao programa por parte dos participantes aos grupos.

Palavras-chave: Grupo de pais; família; parentalidade; práticas educativas

\begin{abstract}
This work refers to interventions performed in the specific internship in Psychology with a group of parents in a program called EducaPais. The program aimed to develop parental skills. As a result of an experience report, this article theoretical approach is Positive Psychology, paternal practices and styles, social skills and bioecological theory of human development. The program comprises nine weekly meetings lasting an hour and a half each, and is based on the contributions and knowledge of psychology on parental practices and styles. The participants were parents or caregivers of children from zero to eight years old, living in a city on the northern coast of Santa Catarina. The meetings dealt with topics such as child development, anger, valorization of appropriate behaviors of children, inappropriate behaviors and their consequences, discipline, importance of routine, limits, parental styles and social skills. The themes related to parenting and the relationship between parents / caregivers and children were discussed based on the different forms of family configuration existing in the group. The results show that programs in this format contributes to the participants' knowledge of parenting and efficient models, and also improve their parental skills and practices. This makes possible the creation of a safe and healthy environment, enabling parents to realize the need for active involvement in the creation of children. The work with groups as a place for sharing, made possible an exchange of experiences among the participants for an understanding of the similarities of their experiences and a preparation of plans to modify their reality. It has also contributed to the re-signification and problematic of current educational practices and to a change of behavior regarding the behavior of the children. Among the challenges encountered, the difficulty of adherence to the program by the participants to groups stands out.
\end{abstract}

Keywords: Group of parents; family; parenting; educational practices

\title{
Resumen
}

Este trabajo se refiere a las intervenciones realizadas en el estadio específico en Psicología con grupo de padres en el programa denominado EducaPais. El programa tuvo como objetivo el desarrollo de habilidades parentales. Fruto de un relato de experiencia, el presente trabajo tuvo como enfoque teórico la Psicología Positiva, prácticas y estilos parentales, habilidades sociales y la teoría bioecológica del desarrollo humano. El programa comprende nueve encuentros semanales con una duración de una hora y media cada uno, siendo pautados en las contribuciones y saberes de la psicología sobre las prácticas y estilos parentales. Participaron de los grupos padres o cuidadores de niños de cero a ocho años de edad, residentes en una ciudad del litoral norte catarinense. Los encuentros abordaron temas como desarrollo infantil, rabia, valorización de los comportamientos adecuados de los niños, comportamientos inadecuados y sus consecuencias, disciplina, importancia de la rutina, establecimiento de límites, estilos parentales y habilidades sociales. 
Los temas trabajados relacionados con la parentalidad y la relación entre padres / cuidadores e hijos se discutieron a partir de las diferentes formas de configuración familiar existentes en el grupo. Los resultados encontrados indican que los programas en este formato contribuyen a que los participantes conozcan los modelos parentales eficaces y positivos, así como mejoren las competencias y prácticas parentales. Esto posibilita la creación de ambientes seguros y saludables, en los cuales los padres perciben la necesidad de la participación activa en la crianza de los hijos. El trabajo con grupos como espacio de compartir, posibilitó el intercambio de experiencia entre los participantes para la comprensión de las semejanzas de sus vivencias y la elaboración de planes para modificar su realidad. También contribuyó a la resignificación y problematización de prácticas educativas vigentes y para el cambio de conducta ante los comportamientos de los hijos. Entre los desafíos encontrados, se destaca la dificultad de adhesión por parte de los participantes a los grupos.

Palabras clave: Grupo de padres; familia; parentalidad; prácticas educativas

\section{Introdução}

É no ambiente familiar que se inicia a educação para o convívio em sociedade, onde a criança aprende regras, valores morais e padrões de conduta para facilitar essa convivência e o seu desenvolvimento (Donoso \& Ricas, 2009; Patias, Siqueira, \& Dias, 2013). É importante ressaltar que os papéis de mãe e pai se ajustam a idade da criança, assim como a época. É preciso haver ordem e regularidade para educar uma criança e é preciso que os pais sejam o modelo para ela (Weber, 2007).

O ambiente familiar da criança pode se constituir como um ambiente de proteção para seu desenvolvimento ou um ambiente de riscos, variando de acordo com o contexto, costumes e práticas parentais utilizadas pelos cuidadores (Andrade et al., 2005; Maia \& Williams, 2005). Atualmente, os pais demonstram estar com dificuldades para lidar com a educação dos seus filhos no que se refere principalmente aos limites (Carvalho \& Silva, 2014; Gomide, 2009; Levandowski et al., 2016; Rinhel-Silva, Constantino, \& Rondini, 2012). Portanto, ressalta-se a necessidade de um olhar atento para a relação familiar estabelecida, considerando as práticas educativas utilizadas, as quais podem ser positivas ou negativas.

Diante destes fatores, surgiram diversos programas e pesquisas internacionais de trabalho com grupo de pais para a promoção das práticas parentais positivas, com bons resultados no que se refere à adoção destas práticas em detrimento das práticas negativas, bem como mudanças de comportamento dos pais e cuidadores em relação às suas crianças(Coutinho, 2012; Hjelte, Sjöberg, Westerberg, \& Hyvönen, 2015; Murta, Rodrigues, Rosa, \& Paulo, 2012; Pimentel \& Dias, 2012; Pluciennik, \& Chicaro, 2015; Porzig-Drummond, Stevenson, \& Stevenson, 2014; Stewart-Brown et al., 2004). Para Tavares (2015) e Silva et al. (2015), o trabalho em grupos e oficinas de parentalidade possibilita aos participantes o conhecimento, a troca de experiências e o aprendizado de novas maneiras de conduzir a educação dos filhos. 
No Brasil, há muitas pesquisas relacionadas à parentalidade e ao envolvimento parental, entretanto, os programas e grupos de pais e sobre seu papel nas mudanças de comportamento destes ainda são pouco divulgados, bem como sobre a importância do trabalho em grupos para estimular o uso de práticas parentais positivas ao invés de outras estratégias de educação (Murta et al., 2012; Pluciennik, et al., 2015).

A proposta deste artigo enquanto relato de experiência, justifica-se no fato de que atualmente os pais demonstram estar com dificuldades para lidar com a educação dos seus filhos, assim, torna-se relevante orientá-los quanto à forma de lidar com seus filhos e educá-los (Carvalho \& Silva, 2014; Gomide, 2009; RinhelSilva et al., 2012). Na medida em que se apresentam informações sobre uma experiência exitosa com grupos de pais e como este tornou-se um ambiente de compartilhamento de experiências, troca de informações e orientações sobre práticas educativas e estilos parentais, percebe-se ser esta uma modalidade pouco descrita na literatura brasileira (Murta et al., 2012; Pluciennik et al., 2015).

Frente a isso, destaca-se a importância da família como fonte de proteção ou risco para a criança, as atuais dificuldades enfrentadas pelos pais em como educar seus filhos e às possíveis consequências negativas que podem ser geradas por práticas parentais inadequadas, torna-se importante as contribuições da Psicologia na orientação dos pais para que estes possam ser capazes de promover o ambiente mais favorável para o desenvolvimento de seus filhos, evitando conflitos e problemas futuros.

\section{Família e infância}

A família pode ser definida como um conjunto de pessoas conectadas por laços de sangue ou por conviverem em uma mesma residência. $O$ contexto em que estas famílias vivem, ou seja, o contexto familiar, é um importante aspecto a ser investigado, pois é o primeiro ambiente social em que a criança está inserida e impacta seu processo de desenvolvimento (Bossardi \& Vieira, 2015).

$\mathrm{Na}$ infância, a família é considerada o principal apoio ao indivíduo. Ela é um dos agentes mais importantes no processo de socialização e é no ambiente familiar que os indivíduos constroem inicialmente suas crenças, valores, regras, atitudes, cultura, incluindo os comportamentos que são considerados adequados nesta cultura (Benchaya, Bisch, Moreira, Ferigolo, \& Barros, 2011; Pasquali et al., 2012). Atualmente, os pais demonstram estar com dificuldades para lidar com a educação dos seus filhos, no que se refere principalmente aos limites, assim, torna-se relevante orientá-los quanto à forma de se relacionar com seus filhos e educá-los (Carvalho \& Silva, 2014; Gomide, 2009; Rinhel-Silva et al., 2012). Considerando a importância da família na construção de um ambiente ideal para o desenvolvimento da criança, é relevante que a mesma seja orientada em relação as formas que utiliza para educar os filhos.

Rinhel-Silva, Constantino e Rondini (2012) consideram importante considerar a conduta dos pais em relação aos filhos, pois esta está ligada à colocação de regras e limites que auxiliarão a criança a construir seu referencial de atitudes e sua conduta em sociedade. 
Para lidar com a realidade e o mundo que a cerca, a criança precisa desenvolver um repertório cada vez mais elaborado de habilidades sociais. As habilidades sociais se referem às diversas classes de comportamentos sociais de um indivíduo que contribuem para a sua competência social. E esta, é a capacidade do indivíduo de articular pensamentos, sentimentos e ações em função de objetivos pessoais e das demandas existentes, gerando consequências positivas (Del Prette \& Del Prette, 2009).

Para Del Prette e Del Prette (2009), as classes de habilidades relevantes na infância são: autocontrole e expressividade emocional, civilidade, empatia, assertividade, fazer amizades, solução de problemas interpessoais e habilidades sociais acadêmicas. Sendo estas classes de habilidades interdependentes e complementares e compreendendo as principais demandas interpessoais da infância, a aprendizagem de comportamentos sociais inicia-se principalmente com a família e depois se expande para outros ambientes.

Considerando-se a família como o principal meio para o desenvolvimento de habilidades sociais na infância, as habilidades sociais dos próprios pais, ao interagirem e educarem seus filhos, parecem ser cruciais à promoção do desenvolvimento na infância e sua falta pode contribuir para problemas de comportamento. Ou seja, é importante que os pais/cuidadores tenham desenvolvidos em si mesmos as habilidades sociais necessárias para a vida, para assim poderem propiciar e auxiliar no desenvolvimento de seus filhos, pois, às vezes, quando o comportamento dos pais é prejudicial à criança, torna-se necessário modificá-lo (Bolsoni-Silva \& Marturano, 2008).

\section{Teoria Bioecológica do desenvolvimento}

A teoria Bioecológica do desenvolvimento de Urie Bronfenbrenner sugere que o desenvolvimento humano seja analisado através da interação de quatro núcleos inter-relacionados: o processo, a pessoa, o contexto e o tempo. Para esta teoria, as diversas formas de interação das pessoas ocorrem como um processo na relação entre o ambiente e as características da pessoa em desenvolvimento. O processo é o principal mecanismo responsável pelo desenvolvimento. É visto através da interação recíproca progressivamente mais complexa de um ser humano com as pessoas, objetos e símbolos presentes no seu ambiente imediato. Estas formas de interação no ambiente imediato são denominadas como processos proximais (Cecconello \& Koller, 2003).

Outro aspecto a ser discutido no modelo de Bronfenbrenner é a pessoa. Segundo Cecconello e Koller (2003), a pessoa, nesta teoria, é analisada através de suas características determinadas biologicamente, psicologicamente e aquelas construídas na sua interação com o ambiente, consideradas tanto produtoras como produtos do desenvolvimento.

Ainda segundo a teoria Bioecológica, a pessoa faz parte de quatro sistemas concêntricos, ou seja, contextos que se encaixam um dentro do outro do menor nível para o nível mais amplo: microssistema, mesossistema, exossistema e macrossistema. O contexto caracteriza-se por qualquer condição fora do sujeito que pode influenciar o mesmo ou ser influenciado por ele. Os microssistemas são 
contextos onde ocorrem as interações face a face, são considerados o centro gravitacional dos indivíduos. Um exemplo deste sistema é a família. Os mesossistemas consistem na interação entre dois ou mais microssistemas nos quais a pessoa está inserida. A comunidade é um exemplo deste sistema. E o exossistema se refere a um contexto que influencia o indivíduo, sem que ele se encontre inserido no mesmo. O trabalho dos pais pode ser considerado um exossistema para a criança. Por fim, é considerado um macrossistema o contexto mais amplo, que se constitui por todos os padrões globais do micro, meso e exossistema, incluindo a cultura, as crenças, valores e costumes que direcionam os comportamentos da sociedade (Collodel-Benetti, Vieira, Crepaldi, \& RibeiroSchneider, 2013).

O tempo também é considerado como um fator importante para a teoria de Bonfrenbrenner e é analisado em três níveis: microtempo, mesotempo e macrotempo. O microtempo se relaciona à continuidade e à descontinuidade dos processos proximais. A efetividade destes processos está condicionada à ocorrência de uma interação progressivamente mais complexa e recíproca, ocorrida em um período de tempo relativamente regular. O mesotempo se refere à frequência de processos proximais através de intervalos de tempo maiores, pois os efeitos acumulados destes processos geram resultados importantes no desenvolvimento. O macrotempo refere-se a eventos e mudanças dentro da sociedade e a forma como estes eventos afetam e são afetados pelos processos, causando impacto no desenvolvimento humano. Por fim, a pessoa deve ser analisada em relação aos acontecimentos de sua vida dentro destes três níveis do tempo, pois as mudanças ocorridas através do tempo são também produtores da mudança histórica (Cecconello \& Koller, 2003).

\section{As Práticas Parentais}

Diversos autores estudam as várias formas das relações estabelecidas pelos pais com seus filhos com o objetivo de educá-los, dentre as quais pode-se encontrar as práticas parentais. Estas práticas caracterizam-se como as diferentes estratégias e técnicas usadas pelos pais para orientar o comportamento dos filhos (Nogueira \& Rodrigues, 2013).

Gomide e Paixão (2005) definem sete práticas parentais: monitoria positiva, comportamento moral, abuso físico, punição inconsistente, disciplina relaxada, monitoria negativa e negligência. Segundo as autoras, as duas primeiras são práticas parentais consideradas positivas, ou seja, práticas adequadas ao desenvolvimento infantil e que promovem o desenvolvimento de habilidades prósociais. E as práticas restantes são consideradas negativas, podendo desencadear problemas no desenvolvimento infantil e ao desenvolvimento de comportamentos antissociais.

Segundo Gomide et al. (2005) e Salvo, Silvares e Toni (2005), das práticas positivas, a monitoria positiva caracteriza-se por um conjunto de práticas que envolvem a atenção adequada dos pais, o conhecimento deles sobre onde seus filhos se encontram e as atividades por eles realizadas. Também são componentes desse tipo de prática o amor, demonstrações de afeto e apoio e o estabelecimento 
de regras. E a prática relacionada ao comportamento moral está ligada a transmissão dos pais para seus filhos de comportamentos morais, ou seja, normas, valores, o que é certo e errado, através do exemplo, de seus próprios comportamentos, do diálogo e da reflexão junto com a criança, sendo que esta relação deve estar mediada pelo afeto.

Das práticas negativas, há a negligência que se refere à falta de atenção e supervisão dos pais em relação a seus filhos, quando os mesmos se ausentam de suas responsabilidades. A punição inconsistente que envolve uma falha na utilização da punição, acontece quando os pais punem seus filhos de acordo com o seu próprio humor e não em consonância com a gravidade dos atos das crianças, ocorrendo assim uma inconstância nas consequências do comportamento da criança, deixando-a confusa. A monitoria negativa que se refere à grande quantidade de regras e instruções impostas às crianças e o excesso de fiscalização sobre elas. É uma prática que gera muito estresse no ambiente familiar para todos os envolvidos (Gomide, Salvo, Pinheiro, \& Sabbag, 2005).

Ainda para estes autores, em relação às práticas negativas, existe o abuso físico que é considerado a prática de machucar ou causar dor aos seus filhos na tentativa de controlá-los. Abuso físico é diferente de punição física, enquanto o último refere-se a um ato envolvendo força física para punir ou corrigir um determinado comportamento sem a intenção de machucá-la, o abuso físico referese aos atos envolvendo força física constante com o intuito de machucar a criança.

Pais que apresentam práticas adequadas propiciam um ambiente favorável ao desenvolvimento de seus filhos, contribuindo para fortalecimento de fatores de proteção para a criança diante de possíveis ameaças. As práticas parentais positivas também podem evitar o surgimento e/ou perpetuação de problemas. Em contrapartida, práticas parentais inadequadas ou pouco envolvimento dos pais com seus filhos constituem fatores de risco para o desenvolvimento infantil, aumentando a probabilidade da ocorrência de problemas, dependendo da frequência e da intensidade utilizadas (Cia, de Oliveira Pamplin, \& Pereira Del Prette, 2006; Gomide et al., 2005; Turini Bolsoni-Silva \& Marturano, 2008).

\section{Os Estilos Parentais}

O estilo parental pode ser definido como o conjunto de atitudes e comportamentos dos pais na relação com seus filhos relacionados à disciplina, à hierarquia e ao apoio emocional na relação entre eles. Estes estilos podem então ser considerados manifestações dos pais em direção a seus filhos. De maneira geral, existem quatro estilos parentais básicos: autoritário, permissivo, negligente e participativo. É possível que às vezes estes estilos se misturem, dependendo da situação e podem-se apresentar características de mais de um estilo, porém pesquisas demonstram que os pais geralmente apresentam um estilo principal/dominante na relação com seus filhos (Benchaya et al., 2011; Weber, Selig, Galvão Bernardi, \& Viezzer Salvador, 2006; Nogueira \& Rodrigues, 2013; Weber, 2007; Weber, Prado, Viezzer, \& Brandenburg, 2004).

Segundo Weber (2007), os pais autoritários apresentam um alto nível de exigência em relação a seus filhos, porém pouca responsividade. Eles impõem 
muitas regras e limites rígidos e inflexíveis objetivando o controle sobre os filhos e sua obediência. Também não permitem que os filhos participem das decisões, pois somente suas próprias opiniões são consideradas importantes e consideram pouco os sentimentos de seus filhos. Enquanto que pais permissivos apresentam baixo nível de exigência e muita responsividade. Tendem a se comportar de maneira não-punitiva, não se apresentando como um modelo, um agente responsável, mas sim como um recurso para realização dos desejos de seus filhos. Em geral, apresentam dificuldade em dizer "não" em decorrência do medo de não mais serem amados, consideram demais as opiniões e sentimentos de seus filhos, deixando suas próprias opiniões e sua autoridade em segundo plano.

Ainda segundo a autora, os pais com o estilo parental negligente apresentam baixo nível de exigência e de responsividade, estabelecendo pouco ou nenhum limite e demonstrando pouco afeto e participação. Eles não se comprometem com a educação de seus filhos, deixando com que eles façam quase tudo, do jeito que quiserem, se quiserem e quando quiserem. Já o estilo parental participativo envolve alto nível de exigência e responsividade. Os pais deste estilo parental demonstram muito afeto e envolvimento em relação aos filhos, estando disponíveis para ajudar com suas tarefas, brincar, elogiar, mostrar que tem orgulho dos mesmos, ao mesmo tempo em que mantêm sua autoridade, estabelecendo os limites necessários para o desenvolvimento das crianças e adolescentes. São pais mais abertos para conversar com seus filhos, que consideram suas opiniões e sentimentos, assim como permitem que participem de decisões (Weber, 2007).

Segundo pesquisas realizadas por Weber (2007) e Cia, Pamplin e Del Prette (2006), o estilo parental participativo é considerado o mais adequado e favorável, refletindo os melhores resultados possíveis para o desenvolvimento da criança, já os outros estilos trazem algumas dificuldades. Os filhos de pais autoritários tendem a ter um desenvolvimento razoável em relação ao âmbito escolar e comportamento, porém desenvolvem poucas habilidades sociais, problemas de autoestima e altos índices de ansiedade, depressão e estresse. Ao contrário do estilo anterior, filhos de pais permissivos tendem a ter problemas relacionados ao âmbito escolar, comportamento, tolerância a frustração e autonomia, porém apresentam habilidades sociais razoavelmente desenvolvidas e baixo nível de depressão. Já o estilo negligente traz as piores consequências para as crianças, pois filhos de pais com este estilo tendem a apresentar atraso no desenvolvimento e problemas em todos os domínios.

Também é importante ressaltar que os papéis de mãe e pai se ajustam a idade da criança, assim como a época de desenvolvimento da sociedade. É preciso haver ordem e regularidade para educar uma criança e que os pais sejam o modelo (Weber, 2007). Portanto, frente a isso, a importância da família como fonte de proteção ou risco para a criança, as atuais dificuldades enfrentadas pelos pais em como educar seus filhos e às possíveis consequências negativas que podem ser geradas por práticas parentais inadequadas, torna-se importante as intervenções quanto a orientação dos pais para que estes possam ser capazes de promover o ambiente mais favorável para o desenvolvimento de seus filhos, evitando conflitos e problemas futuros. 


\section{Metodologia}

Este trabalho é um relato das atividades realizadas no estágio específico do do Curso de Psicologia da UNIVALI através de um programa de intervenção com pais denominado EducaPais. $O$ estágio propôs a realização de grupos e oficinas com pais e cuidadores de crianças com até os oito anos de idade. $O$ trabalho com os grupos de pais foi denominado Programa EducaPais. O programa foi divulgado na comunidade e realizado gratuitamente.

O Programa EducaPais foi criado com o intuito de promover por meio de atividades, discussões e compartilhamentos de experiências, o desenvolvimento de habilidades parentais e seu aprimoramento para melhor compreender e aprender a lidar com os comportamentos da criança. Através dele buscou-se ensinar modos e técnicas positivas para que os pais compreendam e aprendam a lidar com os comportamentos das crianças. Também auxilia com técnicas para disciplinar os filhos da maneira mais saudável possível. Ele teve como base 0 Programa ACT Para Educar Crianças em Ambientes Seguros, uma iniciativa desenvolvida pelo Escritório de Prevenção da Violência da Associação Americana de Psicologia (APA) para abordar as questões relacionadas à violência e às práticas parentais das famílias americanas e canadenses (Pedro, Altafim, \& Linhares, 2017; Pluciennik et al., 2015; Portwood, Lambert, Abrams, \& Nelson, 2011). O enfoque teórico utilizado para esta intervenção foi a Psicologia Positiva (Araújo, 2013; Paludo \& Koller, 2007), as práticas e estilos parentais (Borges, 2010; Gomide et al., 2005; Gomide, Salvo, Pinheiro, \& Sabbag, 2005; Simões, Farate, \& Pocinho, 2011), habilidades sociais na infância (Del Prette, A. \& Del Prette, 2009) e a teoria bioecológica do desenvolvimento humano (Bronfrenbrenner, 2011).

Salienta-se ainda que o objetivo do programa não foi criticar os pais quanto a forma de educar seus filhos nem Ihes impor um modo correto, mas sim fazê-los refletir sobre suas próprias práticas e mostrar que existem diversas formas de lidar com uma mesma situação, sempre considerando o melhor para o desenvolvimento das crianças.

Optou-se pela realização de três grupos do Programa EducaPais. O Grupo 1 teve como público alvo pais ou cuidadores de crianças de 0 a 8 anos que frequentavam na época um Serviço de Atendimento à Pessoas Surdas. $O$ Grupo 2, após divulgação na comunidade, foi aberto a quaisquer pais ou cuidadores de crianças de 0 a 8 anos, residentes na região e que tivessem interesse na temática. E o Grupo 3 foi realizado com as inscrições remanescentes do Grupo 2.

No ano de 2016 foram realizados três grupos. Cada um deles contou com nove encontros. Os temas dos encontros realizados em cada grupo foram os mesmos, com o intuito de refletir questões relacionadas às práticas parentais, estilos parentais, comportamento e desenvolvimento infantil, entre outros.

Para a avaliação das intervenções, foram realizados pré e pós teste. No primeiro encontro do programa foram aplicados questionários sobre 0 conhecimento que os participantes tinham sobre alguns dos temas que seriam trabalhados nos encontros. $\mathrm{E}$ ao final dele, os mesmos questionários aplicados novamente com o intuito de saber se houve mudança nos conhecimentos dos 
participantes sobre os assuntos em questão. Além destes questionários, foi aplicado um questionário sócio demográfico para identificar o perfil dos participantes. E ao fim do programa, foi aplicado um instrumento com o objetivo de avaliar a qualidade do programa.

\section{Resultados e Discussão}

Os resultados estão distribuídos em 4 categorias para a discussão: perfil dos participantes, os encontros e os grupos de pais/cuidadores, estrutura dos encontros e avaliação do Programa EducaPais. A categoria perfil dos participantes apresenta as características sóciodemográficas dos membros dos grupos; a categoria os encontros e os grupos de pais/cuidadores descreve os objetivos e os temas de cada encontro; a categoria estrutura dos encontros apresenta um breve relato das atividades realizadas em cada encontro; já a categoria avaliação do Programa EducaPais traz a avaliação e percepção dos participantes em relação ao Programa.

\section{Perfil dos Participantes}

Os três grupos do Programa EducaPais realizados no ano de 2016 contaram com a participação de um total de 22 pessoas, cujos dados são apresentados nos gráficos abaixo:

Tabela 1

Distribuição dos participantes por faixa etária

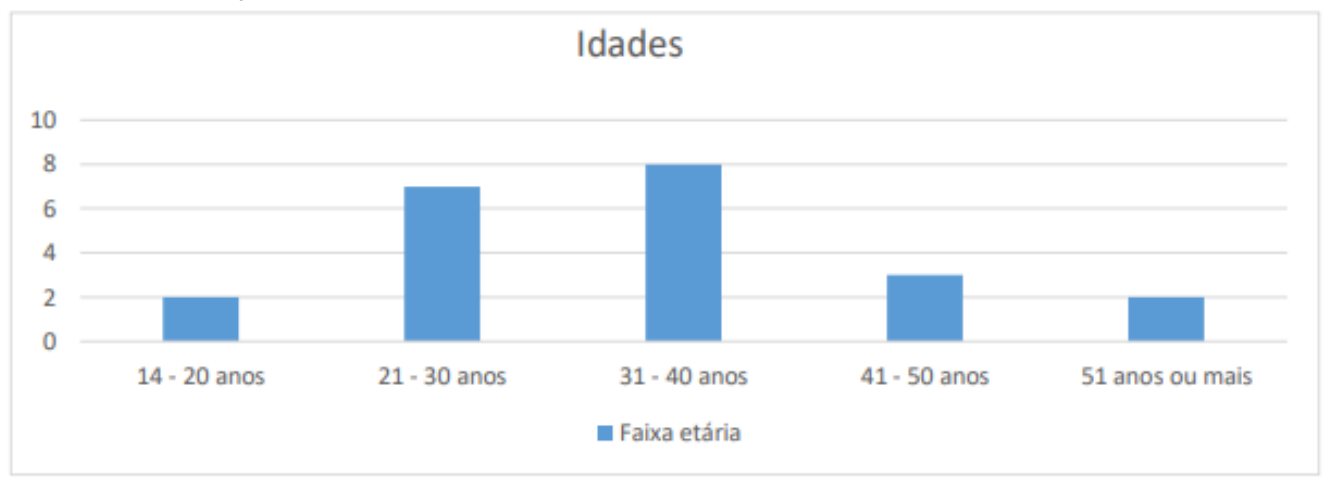

Conforme pode-se analisar, a maior parte dos participantes tinha idade entre 30 e 40 anos, seguidos de pais com idade entre 20 a 30 anos, com uma minoria de idade superior a 41 anos ou inferior a 20 anos. Estes dados diferem moderadamente do último Censo brasileiro, realizado em 2010, o qual aponta que $40,5 \%$ dos responsáveis pela sua família tem entre 40 e 59 anos, seguidos de $31,3 \%$ para pessoas de 25 a 39 anos e $21,9 \%$ para 60 anos ou mais (IBGE Instituto Brasileiro de Geografia e Estatística, 2010). Desta forma, percebe-se que o grupo de pais participantes do programa são mais jovens e se interessam por aprender procedimentos para lidarem com seus filhos.

Tabela 2

Distribuição dos participantes por sexo 


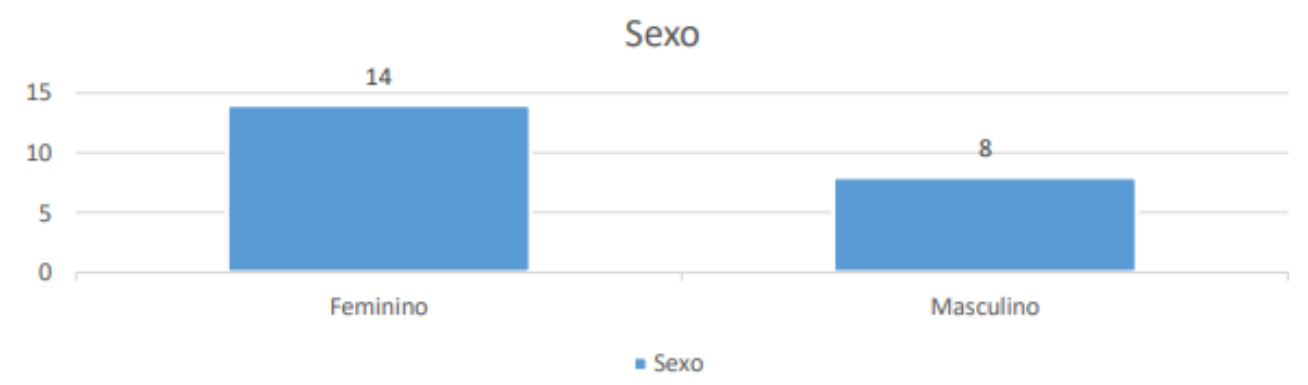

Fonte: Questionário Sociodemográfico,2016.

Conforme apontado no gráfico acima, a maior parte dos participantes eram do sexo feminino. A expressiva quantidade de mulheres participantes dos grupos evidencia a cultura vigente na qual o cuidado dos filhos é delegado ao sexo feminino, enquanto que ao homem cabe o papel de provedor do lar, apesar deste aspecto estar apresentando mudanças com as novas reflexões sobre parentalidade e o papel do pai na educação dos filhos (Borsa \& Nunes, 2011). Isto pode ser verificado no último Censo brasileiro, em que $61,3 \%$ dos responsáveis financeiros pelo domicílio são do sexo masculino (IBGE - Instituto Brasileiro de Geografia e Estatística, 2010).

Tabela 3

Distribuição dos participantes pelo nível de escolaridade

\section{Escolaridade}

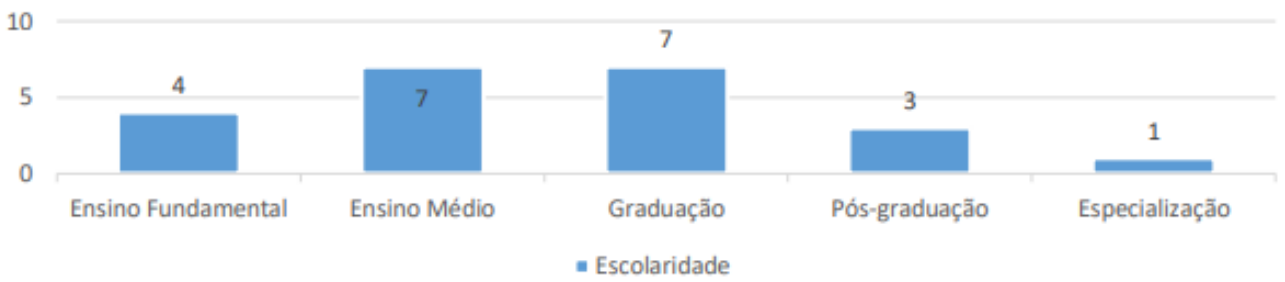

Fonte: Questionário Sociodemográfico, 2016.

O gráfico acima aponta um grau de escolaridade bastante diversificado entre os participantes, visto que a maior parte destes concluiu o Ensino Médio e a Graduação, havendo poucos com pós-graduação ou somente com o Ensino Fundamental completo. Estes dados diferem moderadamente da realidade brasileira atual, que apesar de diversificada, conta com um grande percentual de pessoas maiores de 25 anos ainda com o ensino fundamental incompleto $(50,8 \%$ dos homens e $47,8 \%$ das mulheres) ou fundamental completo e ensino médio incompleto (14,9\% dos homens e $14,4 \%$ das mulheres), seguidos de uma minoria com Ensino Médio completo e Graduação (34\% e 37,5\%, respectivamente) (IBGE - Instituto Brasileiro de Geografia e Estatística, 2010).

Tabela 4

Distribuição dos participantes pelo grau de parentesco com a criança 


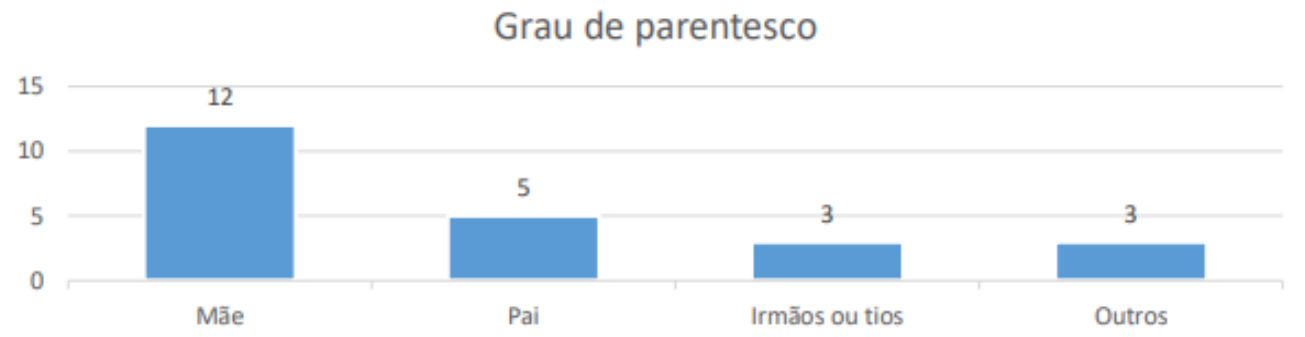

Fonte: Questionário Sócio demográfico, 2016.

Percebe-se que a maior parte dos participantes eram mães, seguido pelos pais, irmãos e tios das crianças. Também participaram dos grupos pessoas sem filhos pequenos, porém ligadas a Educação Infantil. É comum durante a criação dos filhos, os pais e as mães necessitarem do auxílio da família extensa, como primos, tios e avós. Estes devem estar presentes na educação dos pequenos, fornecendo o suporte e carinho necessários, ajudando os pais no enfrentamento das mudanças e das fases de desenvolvimentos de seus filhos (Prati \& Koller, 2011).

Em relação à configuração familiar, os participantes do programa EducaPais apresentaram bastante heterogeneidade nas 13 famílias envolvidas, englobando em sua maioria pais com filho único, seguidos de pais com mais de um filho, pais com filho(s) e agregado(s), mães com filho e agregados. Também participou do grupo um casal sem filhos. Estes dados vão de encontro aos dados obtidos no último Censo brasileiro, no qual as famílias brasileiras cada vez mais contam com uma variedade de membros morando em um mesmo domicílio e com um número cada vez menor de filhos por casal (4,26 a menos em relação à 1940) (IBGE Instituto Brasileiro de Geografia e Estatística, 2010).

\section{Os Encontros e os Grupos de Pais/cuidadores}

Os três grupos realizados do Programa EducaPais abordaram os seguintes temas e objetivos:

\begin{tabular}{|c|c|}
\hline $\begin{array}{c}\text { Compreendendo os for filhos. } \\
\text { comportamentos dos }\end{array}$ & $\begin{array}{l}\text { Compreender os elementos básicos do } \\
\text { desenvolvimento infantil e quais } \\
\text { comportamentos esperar de crianças de idades } \\
\text { diferentes. } \\
\text { Compreender a importância de responder } \\
\text { aos comportamentos de seus filhos com base } \\
\text { no que é adequado para a idade deles. }\end{array}$ \\
\hline $\begin{array}{c}\text { Como os pais podem } \\
\text { entender e controlar sua } \\
\text { raiva. }\end{array}$ & $\begin{array}{l}\text { Entender como ficamos com raiva e o que } \\
\text { podemos fazer para controlar e lidar } \\
\text { com este sentimento. }\end{array}$ \\
\hline $\begin{array}{l}\text { Comportamentos } \\
\text { adequados das crianças e e } \\
\text { sabendo como valorizar } \\
\text { esses comportamentos. }\end{array}$ & $\begin{array}{l}\text { Ensinar os pais como identificar os } \\
\text { comportamentos adequados da criança e } \\
\text { aprender a valorizar esses comportamentos. }\end{array}$ \\
\hline
\end{tabular}




\begin{tabular}{|c|c|}
\hline $\begin{array}{l}\text { Ignorando os } \\
\text { comportamentos } \\
\text { inadequados e aplicando a } \\
\text { disciplina para } \\
\text { comportamentos positivos. }\end{array}$ & $\begin{array}{l}\text { Demonstrar para os pais a importância de } \\
\text { ignorar os comportamentos inadequados dos } \\
\text { filhos para que estes não mais ocorram. }\end{array}$ \\
\hline $\begin{array}{l}\text { Estabelecendo regras e } \\
\text { limites/rotina. }\end{array}$ & $\begin{array}{l}\text { Compreender a importância do } \\
\text { estabelecimento de regras, limites e rotinas } \\
\text { tanto para os filhos quanto para os pais. }\end{array}$ \\
\hline $\begin{array}{l}\text { Consequências } \\
\text { negativas para a disciplina e } \\
\text { a violência na vida das } \\
\text { crianças. }\end{array}$ & $\begin{array}{l}\text { Auxiliar os pais a aprender maneiras de } \\
\text { disciplinar seus filhos, demonstrando que cada } \\
\text { comportamento possui suas consequências e } \\
\text { demonstrar como as crianças podem estar } \\
\text { expostas à violência e no que isso afetará suas } \\
\text { vidas. }\end{array}$ \\
\hline $\begin{array}{l}\text { Disciplina e estilos } \\
\text { parentais. }\end{array}$ & $\begin{array}{l}\text { Ajudar os pais a entender que a forma } \\
\text { como educam seus filhos tem um impacto sobre } \\
\text { o comportamento deles por toda a vida. }\end{array}$ \\
\hline $\begin{array}{l}\text { Habilidades sociais na } \\
\text { infância. }\end{array}$ & $\begin{array}{l}\text { Tornar conhecida aos pais algumas } \\
\text { habilidades sociais importantes tanto na infância } \\
\text { quanto na vida adulta. }\end{array}$ \\
\hline Revisão dos encontros. & $\begin{array}{l}\text { Revisar os conteúdos trabalhados ao } \\
\text { longo dos } 8 \text { encontros realizados. Estimular os } \\
\text { participantes a transmitir para outras pessoas o } \\
\text { que aprenderam. Realizar a avaliação do } \\
\text { programa. }\end{array}$ \\
\hline
\end{tabular}

No início de cada encontro foi realizado uma dinâmica de aquecimento com o objetivo preparar o grupo para as atividades a serem realizadas posteriormente, servindo para descontrair o ambiente, conhecer o grupo, apresentar as pessoas umas às outras, deixando o ambiente mais propício aos aprendizados (Matos Barreto Mota \& Bouttelet Munari, 2006).

As estratégias utilizadas ao longo dos encontros foram rodas de conversa/círculo de cultura e atividades, buscando promover discussões e compartilhamentos de experiências. Paulo Freire (2014) defendia a reflexão e a construção do conhecimento a partir do conhecimento das pessoas pelo coordenador de debates, que participa do grupo e dialoga com os outros participantes. Os encontros utilizavam o diálogo e os conteúdos foramelaborados a partir das situações cotidianas acessíveis aos participantes, com o objetivo de desafiar os grupos, levando-os através da reflexão a posições mais críticas para que os participantes, fossem parte do trabalho de mudarem as suas vidas e a sociedade em que estão inseridos (Rameh, 2005).

Além das técnicas utilizadas a cada encontro, uma estratégia recorrente foi a indicação de tarefas ao final de cada encontro para os participantes realizarem em casa com os filhos visando reforçar o tema trabalhado (Santos \& Leite, 2013). 


\section{Estrutura dos encontros}

Encontro 1 - Compreender os comportamentos dos filhos. O tema principal trabalhado neste dia foi o desenvolvimento infantil e como entender e lidar com os filhos nos diferentes estágios de seu desenvolvimento. De acordo com Macarini, Martins, Minetto, Vieira (2010), e Silveira (2011), a maneira com que pais e cuidadores compreendem o comportamento das crianças está relacionado a fatores sociais, aspectos individuais e ao contexto histórico em que vivem. Os fatores sociais correspondem à influência da comunidade e dos grupos nas experiências educativas que os pais presenciaram/vivenciaram, os aspectos individuais ao modo como significaram e elaboraram estas experiências e o contexto histórico refere-se às condições socioeconômicas e aspectos culturais da sociedade em que os pais e cuidadores encontram-se inseridos.

Encontro 2 - Como os pais podem entender e controlar sua raiva. O tema raiva foi trabalhado neste encontro através de relatos de experiências, discussões sobre as mesmas, o modelo REPENSE indicado pelo Programa ACT e análise de situações problema a partir do modelo apresentado. Del Prette e Del Prette (2009), afirmam que a expressão inadequada da agressividade/raiva ocorre por falta de habilidades sociais. Estas habilidades são necessárias e importantes para a vida dos indivíduos, independentemente de serem crianças ou adultos. Para Tavares (2015) e Silva et al. (2015), o trabalho em grupos e oficinas de parentalidade possibilita aos participantes o conhecimento, troca de experiências e o aprendizado de novas maneiras de conduzir a educação dos filhos. $O$ trabalho sobre as emoções nestes grupos, propicia um reconhecimento dos sentimentos e de maneiras socialmente aceitas para lidar com eles, que podem ser repassados às crianças para promover um desenvolvimento saudável e assegurar que os cuidadores aprendam maneiras de auxiliar os pequenos no reconhecimento e na expressão adequada de seus sentimentos.

Encontro 3 - Identificar os comportamentos adequados das crianças e saber como valorizar esses comportamentos. Neste encontro foi realizada uma atividade sobre comportamentos adequados e inadequados, discutindo-se as maneiras de se aumentar a ocorrência dos bons comportamentos e debatidos termos como reforço, consequência e ameaça. É no ambiente familiar que as crianças constroem inicialmente suas crenças, valores, regras, atitudes, cultura, incluindo os comportamentos que são considerados adequados nesta cultura (Benchaya et al., 2011; Pasquali et al., 2012). Assim, cabe a família ensinar a criança quais são os comportamentos adequados que devem ser apresentados e saber como valorizá-los.

Encontro 4 - Ignorar os comportamentos inadequados e disciplina para comportamentos positivos. Este tema foi trabalhado a partir do uso de vídeos, discussão e role play. Segundo Alvarenga e Piccinini (2009), muitos pais costumam ser pouco assertivos, além de não reforçarem positivamente aspectos adequados da conduta dos filhos, acabam por reforçar positivamente comportamentos inadequados das crianças. Isto pode gerar problemas para o desenvolvimento infantil. 
Encontro 5 - Estabelecer regras e limites/rotina. Neste encontro, foi discutido com o grupo a importância das regras e da rotina na vida das crianças, bem como as maneiras de colocá-las em prática. $\mathrm{O}$ grupo dialogou sobre os métodos que utilizam para ensinar regras e impor limites aos seus filhos, havendo também a troca de experiências relacionadas ao tema entre os participantes. Para Patias, Siqueira e Dias (2013), é no ambiente familiar que há a educação para o convívio em sociedade, onde a criança aprende regras, valores morais e padrões de conduta para facilitar essa convivência e o seu desenvolvimento. Estas regras, valores morais e condutas são ensinadas aos filhos por meio de práticas parentais, ou seja, por meio de estratégias utilizadas pelos genitores a fim de educar sua prole, como a utilização de explicações, punições ou, até mesmo, recompensas. Geralmente, essas práticas visam amenizar comportamentos inadequados e incentivar a ocorrência de comportamentos adequados.

Encontro 6 - A disciplina e a violência na vida das crianças. Os temas trabalhados incluíram principalmente as consequências negativas dos comportamentos inadequados das crianças e quais técnicas utilizar, assim como os tipos de violência e também sua influência na vida das crianças. Neste encontro, os participantes relembraram o que aprenderam durantes todo o programa e relataram as suas principais dificuldades para educar seus filhos quando estes apresentam comportamentos inadequados. Para Ritter et al. (2014), o trabalho em grupos voltados para a reflexão de temas e troca de experiências é importante na medida em que se torna uma oportunidade de discussão de assuntos de interesse comuns e de contemplações que podem influenciar positivamente as condições de vida de seus participantes. Brito et al. (2010), aponta que o trabalho com pais e mães em grupos possibilita que estes troquem experiências com seus semelhantes e reflitam sobre diversos aspectos que interferem em seu contexto, mas que muitas vezes não podem ser compartilhados com a família devido a brigas, separações ou grandes distâncias.

Encontro 7 - Disciplina e estilos parentais. O tema foi trabalhado através de vídeos e discussão. De acordo com Fonsêca et al. (2014), as pesquisas mostram que os estilos parentais estão relacionados a diversos aspectos do desenvolvimento psicossocial de crianças e adolescentes, como, por exemplo, autoestima, ajustamento social, psicopatologia e desempenho escolar, sendo ainda relacionados aos estímulos nos filhos para a disciplina, a independência, a autonomia e a responsabilidade, ao mesmo tempo em que modelam os comportamentos considerados adequados socialmente pelos pais.

Encontro 8 - Habilidades sociais na infância. Os membros dos grupos participaram de diversas atividades lúdicas com o intuito de trabalhar algumas habilidades sociais, como o reconhecimento de emoções, a resolução de problemas e a assertividade. Segundo Bolsoni-Silva e Marturano (2002) e Pinheiro et al. (2006), a maneira como os pais educam seus filhos e a forma como interagem com eles é de crucial importância para a promoção de comportamentos socialmente adequados nas crianças. Assim, os pais precisam se comportar de forma socialmente adequada, sendo socialmente habilidosos, para que seus filhos aprendam a se comportar desta forma. Desta forma, os pais devem ser modelos 
para seus filhos e devem incentivar comportamentos assertivos objetivando promover a competência social dos mesmos.

No último encontro, foi realizada uma atividade lúdica de revisão e outra de socialização das tarefas realizadas em casa pelos participantes. Para Ritter et al. (2014), o grupo é uma oportunidade de discussão de assuntos de interesse comuns e de reflexões que podem refletir positivamente nas condições de vida de seus participantes, além da socialização de saberes técnico-científicos e populares e da troca de experiências.

\section{Avaliação do programa EducaPais}

Para a avaliação da eficácia das intervenções realizadas com os grupos, foram aplicados no início e ao final do programa questionários relativos aos temas desenvolvimento infantil, comportamento dos pais e estilos parentais. Por fim, os instrumentos foram analisados frente aos conhecimentos debatidos nos encontros.

Em relação ao desenvolvimento infantil, inicialmente todos os participantes demonstraram um nível mínimo de entendimento sobre o assunto. Após os encontros, sete pessoas mantiveram seu nível de conhecimento semelhante, 14 pessoas aumentaram significativamente seus conhecimentos e uma pessoa teve seu questionário anulado por erro no preenchimento do mesmo.

Com o questionário referente ao comportamento dos pais foi possível observar que a maior parte dos participantes entendiam 0 que era 0 comportamento ideal esperado para os pais na relação com seus filhos, porém cometiam alguns comportamentos considerados inadequados nesta relação. Assim, ao final do programa foi possível perceber mudanças significativas no comportamento de cerca de $75 \%$ dos participantes, porém $25 \%$ manteve o mesmo padrão de interação com seus filhos.

Estilos parentais foi o tema com maior aproveitamento, considerando que a maioria dos participantes apresentou um aumento considerável nos seus conhecimentos sobre o assunto.

Assim, é possível concluir, através da análise dos dados levantandos com os participantes, que o Programa EducaPais tem sua eficácia comprovada, considerando os índices positivos na aquisição de novos conhecimentos e informações pertinentes ao objetivo proposto inicialmente. Não se identificou prejuízos para os participantes nem em declínio de seus conhecimentos.

A avaliação final do programa contou com a participação de 22 pessoas. De acordo com o questionário de avaliação do Programa, pôde-se perceber que os resultados alcançados foram positivos, sendo que a maior parte dos participantes gostou do trabalho realizado pelas estagiárias, considerando-as eficientes e com um bom domínio do conteúdo abordado. A maioria também relatou estar satisfeita com o programa, pois este forneceu boas opções para exercer a parentalidade, bem como afirmou que utilizaria as técnicas aprendidas no programa, pois está confiante de que exercerá seu papel materno ou paterno de um modo mais eficaz após a participaçãono programa. Todos afirmaram que recomendariam o programa a outras pessoas e a maioria afirmou que gostaria de continuar se reunindo com o grupo. 
Em relação às contribuições dos recursos do programa para o aprendizado do conteúdo ensinado, foram apontados como efetivos para a aprendizagem do conteúdo as discussões em grupo, disponibilização de material informativo, tarefas de casa, explicações das estagiárias, slides em PowerPoint e o uso de vídeos.

Em relação ao fator mais atrativo do programa, os participantes elencaram como elemento mais satisfatório a oportunidade de fazer novos amigos, aprender coisas novas, os materiais serem de boa qualidade e de fácil compreensão, a atitude simpática e agradável das estagiárias e os lanches organizados pelo grupo.

Quanto ao que os participantes desejariam modificar no programa, estes sugeriram, em sua maioria, passar mais filmes/vídeos, menor quantidade de encontros, carga horária menor, podendo ser reduzida ou dividida em semestres. Dois participantes indicaram a realização de mais encontros. E três outros responderam que não mudariam não nada, pois consideraram o programa ótimo.

\section{Considerações Finais}

Esta experiência buscou incentivar e favorecer o desenvolvimento de habilidades parentais e consequentemente, aumentar as chances de um desenvolvimento mais saudável para as crianças. O modelo Bioecológico de Urie Bronfrenbrenner utilizado para neste estudo constitui um referencial teórico apropriado para a realização de pesquisas e intervenções, pois por meio de sua proposta de interação dos seus principais componentes possibilita abranger diferentes níveis de análise, permitindo estudar a influência do ambiente e dos fatores biológicos e psicológicos para o desenvolvimento das pessoas.

Para atingir os objetivos deste estudo, foram criados os grupos de pais para discutir os assuntos relacionados a estes temas e propor atividades para conseguir desenvolver mais facilmente estas habilidades.

O Programa procurou fazer a diferença nas famílias na medida em que através de suas atividades e seus encontros promoveu um melhor relacionamento familiar, a compreensão dos pais em relação ao desenvolvimento dos seus filhos. Os encontros foram pautados nas contribuições e saberes da Psicologia sobre as práticas parentais, com o objetivo de desenvolver as habilidades parentais. Importante pensar que para educar pais e cuidadores sobre modelos parentais eficazes e positivos, fortalecer as famílias e melhorar as competências e práticas parentais para criar ambientes seguros e saudáveis, torna-se preciso refletir com os mesmos e fazê-los perceber a necessidade do envolvimento ativo na criação dos filhos.

Assim, sobre os grupos de pais, pode-se concluir que este formato contribuiu para que os participantes conhecessem os modelos parentais eficazes e positivos para o fortalecimento das famílias e melhor as competências e práticas parentais para criar ambientes seguros e saudáveis para seus filhos.

O trabalho com grupos enquanto espaço de compartilhamento, possibilitou a troca de experiência entre os participantes para a compreensão das similaridades de suas vivências e a elaboração de planos para modificar sua realidade. Também contribuiu para a ressignificação e problematização de práticas educativas vigentes e para a mudança de conduta diante dos comportamentos dos filhos. Percebeu-se 
ainda o fortalecimento das redes de apoio e da autonomia dos participantes, características cruciais para um bom exercício da parentalidade.

As observações realizadas pelas facilitadoras durante a realização do programa para pais apontam que os participantes, diante das suas possibilidades, informações e conhecimentos, apresentando-se implicados em ofertar uma boa educação e que promova o desenvolvimento de seus filhos. Os participantes dos grupos refletiram sobre suas próprias práticas e aprenderam novos modos de educar seus filhos.

Portanto, percebe-se que programas e oficinas de formação de pais se constituem como excelentes oportunidades para melhorar os níveis de informação destes, bem como constituem-se em oportunidades para o desenvolvimento de competências educativas parentais, apresentando resultados bastante positivos em relação a percepção de auto eficácia, no desempenho da função parental, entre outros. Da mesma forma, espaços para reflexão e problematização dos aspectos da parentalidade e das práticas parentais promovem a socialização de acadêmicos e profissionais e incitam a proposição de novos modos de pensar e de se atuar nestes contextos.

\section{Referências}

Alvarenga, P., \& Piccinini, C. A. (2009). Práticas educativas maternas e indicadores do desenvolvimento social no terceiro ano de vida. Psicologia: Reflexão e Crítica, 22(2). Recuperado de http://www.redalyc.org/html/188/18815252002/

Andrade, S. A., Santos, D. N., Bastos, A. C., Pedromônico, M. R. M., Almeida-Filho, N. de, \& Barreto, M. L. (2005). Ambiente familiar e desenvolvimento cognitivo infantil: uma abordagem epidemiológica. Revista de Saúde Pública, 39(4), 606-611. https://doi.org/10.1590/S0034-89102005000400014

Araújo, L. F. de. (2013). A psicologia positiva como fomentadora do bemestar e da felicidade. SciELO Brasil. Recuperado de http://www.scielo.br/scielo.php?pid=S141373722013000400017\&script=sci_arttext

Benchaya, M. C., Bisch, N. K., Moreira, T. C., \& Barros, H. M. T. (2011). Non-authoritative parents and impact on drug use: the perception of adolescent children. Jornal de Pediatria, $O(0)$. https://doi.org/10.2223/JPED.2089

Bolsoni-Silva, A. T., \& Marturano, E. M. (2002). Práticas educativas e problemas de comportamento: uma análise à luz das habilidades sociais. Estudos de Psicologia (Natal), 227-235.

Borges, I. C. N. (2010). Qualidade da parentalidade e bem-estar da criança. In Qualidade da parentalidade e bem-estar da criança. Recuperado de https://estudogeral.sib.uc.pt/handle/10316/15564

Borsa, J. C., \& Nunes, M. L. T. (2011). Aspectos psicossociais da parentalidade: o papel de homens e mulheres na família nuclear. Psicologia Argumento, 29(64), 31-39. 
BOSSARDI, C. N, \& VIEIRA, M. L. (2015). Ser mãe e ser pai: integração de fatores biológicos e culturais. In Novo pai: percursos, desafios e possibilidades $\left(1^{\circ} \mathrm{ed}\right)$. Curitiba: Juruá.

Brito, L. M. T. de, Cardoso, A. R., \& Oliveira, J. D. G. de. (2010). Debates entre pais e mães divorciados: um trabalho com grupos. Psicologia: Ciência e Profissão, 30(4), 810-823. https://doi.org/10.1590/S141498932010000400011

Bronfenbrenner, U. ([s.d.]). Bioecologia do Desenvolvimento Humano: Tornando os Seres Humanos mais Humanos. Artmed Editora.

Carvalho, M. S. D. P. de, \& Silva, B. M. B. (2014). ESTILOS PARENTAIS: UM ESTUDO DE REVISÃO BIBLIOGRÁFICA. Revista Psicologia em Foco, 6(8), 22-42.

Cecconello, A. M., \& Koller, S. H. (2003). Inserção ecológica na comunidade : uma proposta metodológica para o estudo de famílias em situação de risco. Recuperado de http://www.lume.ufrgs.br/handle/10183/25676

Cia, F., de Oliveira Pamplin, R. C., \& Pereira Del Prette, Z. A. (2006). Comunicação e participação pais-filhos: Correlação com habilidades sociais e problemas de comportamento dos filhos. Paidéia, 16(35). Recuperado de http://www.redalyc.org/html/3054/305423756010/

Collodel-Benetti, I., Vieira, M. L., Crepaldi, M. A., \& Ribeiro-Schneider, D. (2013). Fundamentos de la teoría bioecológica de Urie Bronfenbrenner. Pensando Psicología, 9(16), 89-99.

Coutinho, M. T. B. (2012). Apoio à família e formação parental. Análise psicológica, 22(1), 55-64.

De, C. G. ([s.d.]). Práticas educativas como forma de predição de problemas de comportamento e competência social Educational practices as behavior and social competence problems predicting issues. Recuperado de http://www.scielo.br/pdf/estpsi/v22n2/v22n2a08

DEL PRETTE, A., \& DEL PRETTE, Z.A.P. (2009). Psicologia das habilidades sociais na infância: teoria e prática $\left(4^{\circ} \mathrm{ed}\right)$. Petrópolis: Vozes. Dobrianskyj Weber, L. N., Selig, G. A., Galvão Bernardi, M., \& Viezzer Salvador, A. P. (2006). Continuidade dos estilos parentais através das gerações-transmissão intergeracional de estilos parentais. Paidéia, 16(35). Recuperado http://www.redalyc.org/html/3054/305423756011/

Donoso, M. T. V., \& Ricas, J. (2009). Perspectiva dos pais sobre educação e castigo físico. Revista de Saúde Pública, 43(1), 78-84.

dos Santos Paludo, S., \& Koller, S. H. (2007). Psicologia Positiva: uma nova abordagem para antigas questões. Paidéia, 17(36). Recuperado de http://www.redalyc.org/html/3054/305423757002/

EMOÇÕES, INTELIGENNCIA EMOCIONAL E PARENTALIDADE - PDF. ([s.d.]). Recuperado de http://docplayer.com.br/43237094-Emocoesinteligencia-emocional-e-parentalidade.html

Gomide, P. I. C. (2009). The influence of profession on maternal parenting styles according to children's perception. Estudos de Psicologia (Campinas), 26(1), 25-34.

Freire, P. (2014). Educação e mudança (1.ed). Rio de Janeiro: Editora Paz e Terra. 
Gomide, P. I. C., Salvo, C. G. de, Pinheiro, D. P. N., \& Sabbag, G. M. (2005). Correlação entre práticas educativas, depressão, estresse e habilidades sociais. Psico-USF, 10(2), 169-178. https://doi.org/10.1590/S1413-82712005000200008

Hjelte, J., Sjöberg, M., Westerberg, K., \& Hyvönen, U. (2015). From Thought to Action: Young Parents' Reasons for Participation in Parenting Support Groups at Child Welfare Centers. Social Work in Public Health, 30(6), 516-533. https://doi.org/10.1080/19371918.2015.1073646

IBGE - Instituto Brasileiro de Geografia e Estatística. (2010). censo demográfico 2010 ( $1^{\circ}$ ed). Rio de Janeiro. Recuperado de http://censo2010.ibge.gov.br/apps/atlas/

Levandowski, G., Puntel, C., Hettwer, Á., Santos, A. M. dos, Bohn, M., Souza, G., ... Mello, A. B. G. (2016). OFICINA LÚDICA E GRUPO DE PAIS: UMA EXPERIÊNCIA INOVADORA. Revista Prâksis, 1(0), 47-56. https://doi.org/10.25112/rp.v1i0.433

Macarini, S. M., Martins, G. D. F., Minetto, M. de F. J., \& Vieira, M. L. (2010). Práticas parentais: uma revisão da literatura brasileira. Arquivos Brasileiros de Psicologia, 62(1), 119-134.

Maia, J. M. D., \& Williams, L. C. de A. (2005). Fatores de risco e fatores de proteção ao desenvolvimento infantil: uma revisão da área. Temas em Psicologia, 13(2), 91-103.

Matos Barreto Mota, K. A., \& Bouttelet Munari, D. (2006). UM OLHAR PARA A DINÂMICA DO COORDENADOR DE GRUPOS. Revista Eletrônica de Enfermagem, 8(1). https://doi.org/10.5216/ree.v8i1.931

Monteiro, E. M. L. M., \& Vieira, N. F. C. (2010). Educação em saúde a partir de círculos de cultura. Revista Brasileira de Enfermagem, 63(3), 397-403. https://doi.org/10.1590/S0034-71672010000300008

Murta, S. G., Rodrigues, A. C., Rosa, I. de O., \& Paulo, S. G. de. (2012). Avaliação de um programa psicoeducativo de transição para a parentalidade. Paidéia (Ribeirão Preto), 22(53), 403-412. https://doi.org/10.1590/S0103-863X2012000300012

Nogueira, S. C. [UNESP, \& Rodrigues, O. M. P. R. (2013). Práticas parentais e indicadores de ansiedade, depressão e estresse maternos. Aleph, $118 \mathrm{f}$.

Nunes da Fonsêca, P., Oliveira de Andrade, P., Fonsêca dos Santos, J. L., Monteiro Cunha, J. E., \& de Assis Albuquerque, J. H. (2014). Hábitos de estudo e estilos parentais: estudo correlacional. Psicologia Escolar e Educacional, 18(2). Recuperado de http://www.redalyc.org/html/2823/282332471017/

Pasquali, L., Gouveia, V. V., Santos, W. S. dos, Fonsêca, P. N. da, Andrade, J. M. de, \& Lima, T. J. S. de. (2012). Questionário de percepção dos pais: evidências de uma medida de estilos parentais. Paidéia (Ribeirão Preto), 22(52), 155-164. https://doi.org/10.1590/S0103863X2012000200002

Patias, N. D., Siqueira, A. C., \& Dias, A. C. G. (2013). Práticas Educativas e Intervenção com Pais: A Educação como Proteção ao Desenvolvimento dos Filhos. Mudanças - Psicologia da Saúde, 21(1), 29-40. https://doi.org/10.15603/2176-1019/mud.v21n1p29-40 
Paula Inês Gomide. (2004). Pais presentes, pais ausentes: regras e limites ( $1^{\circ}$ ed). Petrópolis: Vozes.

Pedro, M. E. A., Altafim, E. R. P., \& Linhares, M. B. M. (2017). ACT Raising Safe Kids Program to promote positive maternal parenting practices in different socioeconomic contexts. Psychosocial Intervention, 26(2), 63-72. https://doi.org/10.1016/j.psi.2016.10.003

Pimentel, J. S., \& Dias, S. (2012). Importância do fortalecimento das redes informais de apoio: Projecto Oficinas de Pais. In Proceedings do XIX Congresso INFAD-Psicología En Un Mundo En Cambio: Propuestas De Intervención, Lisboa. Recuperado de http://infad.eu/RevistalNFAD/2012/n1/volumen4/INFAD_010424_355363.pdf

Pinheiro, M. I. S., Haase, V. G., Del Prette, A., Amarante, C. L. D., \& Del Prette, Z. A. P. (2006). Treinamento de habilidades sociais educativas para pais de crianças com problemas de comportamento. Psicologia: reflexão e crítica, 19(3), 407-414.

PLUCIENNIK, G. A, C., L., M., \& CHICARO, F. M. (2015). Fundamentos da Família como Promotora do Desenvolvimento Infantil - Parentalidade em Foco ( $\left.1^{\circ} \mathrm{ed}\right)$. São Paulo: Fundação Maria Cecília Souto Vidigal. Recuperado de http://www.fmcsv.org.br/pt-br/acervodigital/Paginas/fundamentos-da-familia-como-promotora-do-

desenvolvimento-infantil-parentalidade-em-foco.aspx

Portwood, S. G., Lambert, R. G., Abrams, L. P., \& Nelson, E. B. (2011). An Evaluation of the Adults and Children Together (ACT) Against Violence Parents Raising Safe Kids Program. The Journal of Primary Prevention, 32(3-4), 147-160. https://doi.org/10.1007/s10935-0110249-5

Porzig-Drummond, R., Stevenson, R. J., \& Stevenson, C. (2014). The 12-3 Magic parenting program and its effect on child problem behaviors and dysfunctional parenting: A randomized controlled trial. Behaviour Research and Therapy, 58, 52-64. https://doi.org/10.1016/j.brat.2014.05.004

Prati, L. E., \& Koller, S. H. (2011). Relacionamento conjugal e transição para a coparentalidade: perspectiva da psicologia positiva. Psicologia Clínica, 23(1), 103-118. https://doi.org/10.1590/S010356652011000100007

Rameh, L. (2005). Método Paulo Freire: Uma contribuição para a história da educação brasileira. V Colóquio Internacional Paulo Freire-Recife, 19. Recuperado de http://www.musicaeeducacao.ufc.br/Para\%20o\%20site/Revistas\%20e\% 20peri\%C3\%B3dicos/Educa\%C3\%A7\%C3\%A3o/Paulo\%20Freire.pdf

Rinhel-Silva, C. M., Constantino, E. P., \& Rondini, C. A. (2012). Família, adolescência e estilos parentais. Estudos de Psicologia (Campinas), 221-230.

Ritter, C. B., Aires, M., Rotoli, A., \& Santos, J. L. G. dos. (2015). Grupo como tecnologia assistencial para o trabalho em enfermagem na saúde coletiva. Saúde \& Transformação Social / Health \& Social Change, 5(3), 83-90. 
Santos, E. L. N. dos, \& Leite, F. L. (2013). A distinção entre reforçamentos positivo e negativo em livros de ensino de análise do comportamento. Perspectivas em análise do comportamento, 4(1), 1019.

Silva, L. M., Aragão, A. de S., Julião, C. H., Terassi, G., Mata, J. J. da, Chagas, L. M. de O., ... Silva, L. C. C. de M. (2015). Oficinas de Parentalidade. ParticipAção, $O(27), 18-26$.

Silveira, F. F. (2011). Interventions with parents: the modification of parental practices and the inclusion of contextual variables. Estudos de Psicologia (Natal), 16(3), 279-284.

Simões, S., Farate, C., \& Pocinho, M. (2011). Estilos Educativos Parentais e Comportamentos de Vinculação das Crianças em Idade Escolar. Interações: Sociedade e as novas modernidades, 11(20). Recuperado de http://www.interacoesismt.com/index.php/revista/article/view/275

Stewart-Brown, S. (2004). Impact of a general practice based group parenting programme: quantitative and qualitative results from a controlled trial at 12 months. Archives of Disease in Childhood, 89(6), 519-525. https://doi.org/10.1136/adc.2003.028365

Turini Bolsoni-Silva, A., \& Marturano, E. M. (2008). Habilidades sociais educativas parentais e problemas de comportamento: Comparando pais e mães de pré-escolares. Aletheia, (27). Recuperado de http://www.redalyc.org/html/1150/115012525010/

WEBER, L. N. D. ([s.d.]). EDUQUE COM CARINHO - PARA PAIS: EQUILIBRIO ENTRE AMOR E LIMITES. JURUA EDITORA.

Weber, L. N. D., Prado, P. M., Viezzer, A. P., \& Brandenburg, O. J. (2004). Identificação de estilos parentais: o ponto de vista dos pais e dos filhos. Psicologia: reflexão e crítica, 17(3), 323-331. 